\title{
CARACTERIZAÇÃO DE GENÓTIPOS DE TRITICALE PARA TOLERÂNCIA À GERMINAÇÃO NA ESPIGA
}

\author{
${ }^{1}$ Carlos Henrique dos Santos Fernandes, ${ }^{2}$ Klever Márcio Antunes Arruda \\ ${ }^{1}$ Universidade Norte do Paraná - Graduação em Agronomia, (carloshenrique_fernandes_@hotmail.com). ${ }^{2}$ Eng. Agr. Pesquisador, Instituto \\ Agronômico do Paraná, Londrina, Pr, (klever@iapar.br).
}

RESUMO: A germinação na espiga é uma das principais características a afetar a cultura do triticale (x Triticosecale Wittmack), representando um fator limitante de qualidade tecnológica para a indústria de transformação e de qualidade fisiológica para a produção de sementes. O objetivo deste trabalho foi caracterizar a tolerância/suscetibilidade à GE de genótipos de triticale. Para isso, 30 genótipos de triticale e três de trigo foram semeados, na safra 2016, na Estação Experimental do IAPAR/Londrina. Após a colheita, parte das espigas foi submetida à indução da germinação por nebulização em ambiente protegido, por 48 horas. Transcorridas as 48 horas de nebulização, estas foram trilhadas manualmente para a determinação da porcentagem de grãos germinados (\% GG) do Peso Hectolítrico (PH) com e sem nebulização e o Numero de Queda. A análise variância constatou diferença significativa entre os genótipos de triticale para todas as características avaliadas. Dos 30 genótipos de triticale avaliados, 14 não apresentaram diferença estatística dos genótipos de trigo utilizados como testemunhas. De uma maneira geral, quatro genótipos de triticale (BRS 203, BRS Netuno, BRS Saturno e TPOLO 66) destacaramse por apresentar baixo \% de grãos germinados e manter o peso hectolítrico alto mesmo após serem expostos a 48 horas de nebulização.

.Palavras-chave: qualidade de grãos, enzimas, panificação.

\section{CHARACTERIZATION OF TRITICALE GENOTYPES FOR GERMINATION TOLERANCE IN SPONGE}

ABSTRACT: The germination in the spike is one of the main characteristics to affect the triticale crop ( $x$ Triticosecale Wittmack), representing a limiting factor of technological quality for the industry of transformation and of physiological quality for the production of seeds. The objective of this work was to characterize GE tolerance / susceptibility of triticale genotypes. For this, 30 triticale and three wheat genotypes were sown in the 2016 harvest at the IAPAR / Londrina Experimental Station. After the harvest, part of the spikes were submitted to the induction of germination by nebulization in protected environment, for 48 hours. After 48 hours of nebulization, they were manually tracked to determine the percentage of germinated grains $1 \%$ $\mathrm{GG}$ ) of the Hectolitrico Weight (PH) with and without nebulization and the Number of 
Fall. The variance analysis found a significant difference between the triticale genotypes for all characteristics evaluated. Of the 30 evaluated triticale genotypes, 14 did not present statistical difference of the wheat genotypes used as controls. In general, four genotypes of triticale (BRS 203, BRS Neptuno, BRS Saturno and TPOLO 66) were characterized as having low germinated grains and maintaining a high hectoliter weight even after being exposed to 48 hours of nebulization.

Keywords: $x$ Triticosecale Wittmack; pre-harvest germination; numbness.

\section{INTRODUÇÃO}

O triticale (x Triticosecale Wittmack) é uma gramínea de estação fria obtida através do cruzamento artificial entre o trigo (Triticum sp.) e o centeio (Secale cereale L.), com o propósito de combinar características favoráveis destas duas espécies. O trigo apresenta alto potencial produtivo e excelente qualidade para panificação, mas é exigente em solos férteis e não tolera temperaturas baixas durante parte de seu ciclo. Já o centeio não apresenta características favoráveis à panificação e nem potencial produtivo elevado, mas pode ser cultivado em solos arenosos e mais pobres, em regiões de temperaturas menores que as suportadas pelo trigo. Além disso, apresenta boa resistência a doenças, em especial, à ferrugem da folha e ao oídio. Apesar do triticale não agrupar todas as características desejáveis dos seus genitores, merece destaque sua alta produção de biomassa e maior rendimento de grãos em condições de déficit hídrico e/ou de baixa fertilidade do solo (BONA, 2004; ESTRADA-CAMPUZANO et al. 2012; RANDHAWA et al., 2015).

Em 2014, cerca de 4,135 milhões de hectares de triticale foram cultivados em todo o mundo, sendo a Polônia, Alemanha, Bielorrússia e França os principais países produtores (FAOSTAT, 2016). Segundo estimativa da Companhia Nacional de Abastecimento (CONAB, 2017), a área de triticale colhida no Brasil, na safra 2017, foi de 23,5 mil hectares, com produção total de 68,1 mil toneladas de grãos, dentre as quais cerca de $44 \%$ foi colhida no Paraná em uma área cultivada de 9,7 mil hectares. Tanto no Brasil como nos demais países que cultivam o triticale, os grãos deste cereal são utilizados principalmente para a alimentação animal, e em menor quantidade na alimentação humana, com tendência de aumento do uso da 
farinha para fabricação de pães. Diversos trabalhos comprovam que este cereal pode substituir, em até $75 \%$, o milho utilizado em rações de aves e suínos, obtendo o mesmo ganho de peso e conversão alimentar (NASCIMENTO JUNIOR et al., 2004).

Apesar de apresentar maior competitividade em relação a outros cereais de inverno, as cultivares de triticale ainda possuem deficiências em algumas características agronômicas, tais como a suscetibilidade a certas doenças (giberela, brusone, manchas foliares e viroses) e à germinação em pré-colheita. A germinação pré-colheita (PHS) pode ser definida como a germinação prematura dos grãos na espiga antes da colheita. Isso é causado por períodos de chuvas excessivas e elevada umidade relativa do ar antes da colheita, quando o grão já está maduro. São indicações visíveis de PHS em cereais, entre os quais o triticale, o inchaço dos grãos, descoloração do germe, rompimento do pericarpo e emergência da radícula e mesmo do coleóptilo, em estágios mais avançados.

A germinação precoce ocorre quando a semente entra em contato com água e acontece a embebição, disparando uma sequência de processos fisiológicos, entre os quais, a liberação de hormônios e de enzimas hidrolíticas. Considerando um processo simplificado, a atividade hormonal do ácido giberélico (GA) na semente embebida induzirá a síntese de amilases; as reservas de carboidratos serão hidrolisadas e translocadas para o embrião, onde serão utilizadas no seu desenvolvimento. Segundo Kuo et al. (1996), a função da camada de aleurona dos cereais, durante a germinação, é a secreção de hidrolases, principalmente a alfaamilase, no endosperma. Existem vias de tradução de sinais múltiplas em células da aleurona dos cereais que Ihes permitem modular a produção de hidrolases em resposta aos estímulos hormonais e ambientais. É bem estabelecido que o ácido abscísico (ABA) promove a dormência e reprimi a germinação das sementes, pela redução da produção de amilases, enquanto, que o GA, antagonicamente, desencadeia a germinação das sementes, pela promoção da produção de hidrolases (KUCERA et al., 2005). Ou seja, os hormônios possuem uma forte influência sobre a regulação da dormência e da germinação das sementes. Por sua vez, os genes que codificam as proteínas que modulam o metabolismo destas moléculas sinalizadoras 
(especialmente os envolvidos na biossíntese e desativação de GA e ABA) são os principais reguladores genéticos destes eventos (SEO et al., 2009).

Vários fatores podem contribuir para uma maior tolerância à germinação na espiga, como a redução dos níveis de alfa-amilase nos grãos, a presença de inibidores de germinação, redução da absorção de água pelos grãos e respostas alteradas para hormônios (FLINTHAM, 2000; ZANETTI et al., 2000; HIMI et al., 2002; MARES et al., 2005). Adicionalmente, a falta de dormência adequada das sementes é a principal razão para a PHS, sendo destacada como uma característica governada por múltiplos genes (LI et al., 2004).

O problema da germinação na espiga tem sido observado ao longo de muitos anos e em várias áreas produtoras de triticale e trigo em todo o mundo, representando um fator limitante de qualidade tecnológica para a indústria de transformação e de qualidade fisiológica para a produção de sementes (MOŚ; WÓJTOWICZ, 2004; CHAPMAN, 2011).

Diante do exposto, o objetivo deste trabalho foi caracterizar a tolerância/suscetibilidade à germinação na espiga de genótipos que participaram, em 2016, do bloco de cruzamentos do programa de melhoramento de triticale do IAPAR.

\section{MATERIAL E MÉTODOS}

\section{Material Genético e Local de Condução dos Ensaios}

O bloco de cruzamentos do Programa de Melhoramento do Triticale do IAPAR instalado no ano 2016 foi composto por 30 genótipos, entre os quais seis cultivares com indicação de cultivo para o Brasil, e 24 linhagens avançadas provenientes dos programas de melhoramento genético do IAPAR, da EMBRAPA e do CIMMYT. Assim, inicialmente 30 genótipos de triticale foram caracterizados quanto à resistência à germinação na espiga. Adicionalmente, foram utilizados como testemunhas três genótipos de trigo, a linhagem ND 674 e as cultivares Quartzo e Frontana. A cultivar Frontana é reconhecidamente um dos melhores genótipos de 
trigo quanto à resistência à germinação pré-colheita (BASSOI et al., 2006; FRANCO, 2009; NÖRNBERG, 2012)

Os genótipos foram cultivados na Estação Experimental Sede do IAPAR localizada em Londrina, na safra 2016. Para isso, foram semeadas parcelas compostas por 3 linhas de 2,0 m de comprimento, espaçadas de 0,3 m. Cada parcela foi semeada em três datas, com intervalos de pelo menos uma semana. $O$ propósito do escalonamento da semeadura foi possibilitar a coleta de espigas com maturação fisiológica em uma mesma data.

\section{Metodologias de Avaliação}

As espigas foram colhidas na maturação fisiológica, ou seja, quando perderam a coloração verde, mas os nós dos colmos ainda estavam verdes. Após a colheita, as espigas foram armazenadas em ambiente protegido, até a secagem dos grãos (aproximadamente 13\% de umidade). Transcorrido este período, parte das espigas foi submetida à indução da germinação; outra parte foi trilhada para quantificar o Peso Hectolítrico $(\mathrm{PH})$ dos grãos, e, posteriormente, o Número de Queda (NQ) da farinha integral.

Para induzir a germinação dos grãos de uma maneira mais próxima possível a que ocorreria no ambiente de cultivo, as espigas destacadas no ponto de maturação fisiológica foram submetidas à nebulização em ambiente protegido, por 48 horas. Este método tem sido utilizado com sucesso nos principais programas de melhoramento de trigo do Brasil para a seleção de genótipos resistentes à PHS (BASSOI et al., 2006; FRANCO et al., 2009; OKUYAMA et al., 2017).

O delineamento experimental adotado foi o inteiramente casualizado com duas repetições, sendo a unidade experimental composta por 18 espigas.

\section{Porcentagem de Grãos Germinados}

Transcorridas as 48 horas de nebulização, as espigas foram expostas ao sol para a secagem dos grãos. Posteriormente, procedeu-se uma trilhagem manual das espigas para a avaliação da porcentagem de grãos germinados (\% GG). 
O \% de GG foi determinado a partir da avaliação de duas amostras de 50 grãos, de cada uma das repetições submetidas à nebulização. Para facilitar a visualização da germinação, utilizou-se uma lupa com aumento de 10X.

Foram considerados como grãos germinados aqueles que apresentaram primórdios vegetativos visíveis, ou mesmo ruptura visível do pericarpo.

\section{Falling number}

A análise do $\mathrm{NQ}$ ou falling number foi realizada utilizando-se $7 \mathrm{~g}$ de farinha integral obtida dos grãos não submetidos à nebulização. Após ter sua umidade corrigida para $14 \%$, a farinha foi colocada em tubo viscométrico e adicionada de 25 $\mathrm{mL}$ de água. $\mathrm{O}$ tubo foi imerso em banho-maria a $100^{\circ} \mathrm{C}$ em equipamento "Falling Number" (FN 1500 - Perten Instruments) para agitação e posterior medida do tempo, em segundos, necessário para que o agitador do equipamento caísse, por gravidade, a uma distância fixa, segundo o método 56-81B do AACC (2000).

\section{Peso do Hectolitro}

Para cada um dos 33 genótipos estudados, foram coletadas duas amostras de 15,3 mL dos grãos não submetidos à nebulização (grãos destinados à análise do $N Q$ ), e outras duas amostras dos grãos provenientes das espigas submetidas à nebulização. Após a coleta das amostras de 15,3 mL, estas foram pesadas em balança analítica, e os pesos convertidos para $\mathrm{kg} \mathrm{hL}^{1}$. Adicionalmente, foi determinada a redução de peso hectolítrico $(\mathrm{RPH})$ decorrente da exposição das espigas à nebulização, pela diferença dos $\mathrm{PHs}$ obtidos com grãos sem e com nebulização.

Os dados obtidos para \% GG, NQ, PH (com e sem nebulização) e RPH foram submetidos a análise de variância com o objetivo de detectar a influência dos genótipos sobre os caracteres avaliados. Para diferenciar os efeitos de genótipos, foi realizada a comparação de médias para os cinco caracteres, pelo teste de Scottknott a $5 \%$ de probabilidade de erro. Adicionalmente, os valores obtidos para as cinco variáveis foram comparados utilizando-se a correlação de Pearson. Todas as 
análises estatísticas foram feitas com o auxílio do programa computacional Genes (CRUZ, 2013).

\section{RESULTADOS}

Neste estudo foram avaliados 30 genótipos de triticale e três de trigo (testemunhas) quanto tolerância/suscetibilidade à germinação pré-colheita. Para isso foram determinados o \% GG, após exposição das espigas a 48 horas de nebulização; o NQ e o PH de grãos não submetidos à nebulização; o PH de grão submetidos à nebulização; assim como a RPH decorrente da exposição das espigas à nebulização.

O resumo das análises de variância referente às avaliações nos genótipos de triticale e de trigo é apresentado na Tabelas 1. Os coeficientes de variação experimental (CV) variaram de 0,26 a 31,22\%, o que representa de boa a moderada precisão experimental para os dados coletados neste estudo. A análise variância possibilitou constatar diferença significativa entre os genótipos de triticale para todas as características avaliadas. Além disso, o contraste significativo $(P \leq 0,01)$ triticale vs. trigo revela que existe diferença entre as médias destes dois grupos, para todas as características avaliadas, com exceção da RPH (Tabela 1).

Tabela 1. Resumo das análises de variância dos caracteres \% de Grãos Germinados, Número de Queda, Peso Hectolítrico sem nebulização, Peso Hectolítrico com nebulização e Redução de Peso Hectolítrico de 30 genótipos de triticale e três de trigo, Londrina-PR, safra 2016

\begin{tabular}{|c|c|c|c|c|c|c|}
\hline \multirow{2}{*}{ Fonte de Variação } & \multirow{2}{*}{ GL } & \multicolumn{5}{|c|}{ Quadrado Médio } \\
\hline & & $\% \mathbf{G G}$ & $\mathbf{N Q}$ & PH Sem & PH Com & RPH \\
\hline Tratamentos & 32 & $433,930^{* *}$ & $25150,754^{\star *}$ & $27,434^{\star *}$ & $31,277^{* *}$ & $9,089^{* *}$ \\
\hline Triticale (TCL) & 29 & $440,531^{* *}$ & $8271,963^{\star *}$ & $21,128^{\star \star}$ & $23,264^{\star \star}$ & $9,251^{* *}$ \\
\hline Trigo (TR) & 2 & $2,667^{\mathrm{ns}}$ & $3835,500^{* *}$ & $4,115^{\star *}$ & $1,612^{\text {ns }}$ & $9,485^{\star *}$ \\
\hline TCL vs TR & 1 & $1105,042^{* *}$ & $557266,188^{\star *}$ & $256,938^{* *}$ & $322,980^{* *}$ & $3,623^{\text {ns }}$ \\
\hline Resíduo & 33 & 20,787 & 38,424 & 0,0389 & 0,231 & 0,263 \\
\hline $\mathrm{CV}(\%)$ & & 31,22 & 4,98 & 0,26 & 0,70 & 6,62 \\
\hline
\end{tabular}


O agrupamento de médias, através do método de Scott-knott, possibilitou confirmar a formação de grupos distintos dentro dos genótipos para todas as características avaliadas (Tabela 2). Os valores observados para o caráter \% GG variaram 1 a $54 \%$, ficando os genótipos de trigo agrupados na classe de maior tolerância à germinação. No entanto, dos 30 genótipos de triticale avaliados, 14 (BRS 203, BRS Netuno, BRS Saturno, IPR 111, TCL 13014, TCL 15002, TCL 15008, TCL 15019, TCLD 0717, TLD 1103, TLD 1202, TPOLO 66, TW 13030 e X 092181) não apresentaram diferença estatística $(P \leq 0,05)$ dos genótipos de trigo (Frontana, ND 674 e Quartzo) utilizados como testemunhas tolerantes à GE.

Tabela 2. Médias do \% de Grãos Germinados, Número de Queda, Peso Hectolítrico sem nebulização, Peso Hectolítrico com nebulização e Redução de Peso Hectolítrico de 30 genótipos de triticale e três de trigo, Londrina-PR, safra 2016

\begin{tabular}{|c|c|c|c|c|c|c|c|c|c|c|}
\hline Genótipo & $\% \mathrm{GE}$ & & $\mathrm{NQ}(\mathrm{s})$ & $\mathrm{PH}$ sem (k & & $\mathrm{PH}$ com & $(\mathrm{kg}$ & & $\mathrm{RPH}(\mathrm{kg}$ & $/ \mathrm{hl})$ \\
\hline BRS 203 & 8 & e & $253 \mathrm{~d}$ & $78,7 \quad A$ & $\mathrm{e}$ & 72,1 & B & $d$ & 6,6 & $E$ \\
\hline BRS Harmonia & 46 & a & 62 j & $76,0 \quad A$ & i & 65,6 & B & $\mathrm{h}$ & 10,5 & $\mathrm{C}$ \\
\hline BRS Netuno & 3 & e & $62 \mathrm{j}$ & $78,3 \quad A$ & $f$ & 71,7 & B & $d$ & 6,6 & $E$ \\
\hline BRS Saturno & 2 & e & 79 i & $78,7 \quad A$ & e & 73,6 & B & C & 5,1 & $\mathrm{~F}$ \\
\hline IPR 111 & 2 & e & $63 \mathrm{j}$ & $73,0 \quad A$ & I & 66,2 & B & $\mathrm{h}$ & 6,8 & $E$ \\
\hline IPR Aimoré & 12 & $d$ & $64 \mathrm{j}$ & $79,0 \quad A$ & e & 70,8 & B & e & 8,2 & $D$ \\
\hline ITW 11014 & 36 & b & $124 \mathrm{~g}$ & $74,4 \quad A$ & j & 65,3 & B & $\mathrm{h}$ & 9,1 & D \\
\hline PFT 0609 & 16 & $d$ & $100 \mathrm{~h}$ & $79,0 \quad A$ & e & 72,0 & B & $d$ & 7,0 & $E$ \\
\hline TCL 13003 & 13 & $d$ & $192 \mathrm{e}$ & $80,5 \mathrm{~A}$ & c & 70,6 & B & e & 10,0 & C \\
\hline TCL 13009 & 26 & c & $64 \mathrm{j}$ & $71,8 \quad A$ & $\mathrm{n}$ & 65,9 & B & $\mathrm{h}$ & 5,9 & $E$ \\
\hline TCL 13014 & 7 & e & $62 \mathrm{j}$ & $70,8 \quad A$ & 0 & 62,4 & B & j & 8,4 & D \\
\hline TCL 15002 & 7 & e & $69 \mathrm{j}$ & $77,6 \mathrm{~A}$ & $g$ & 68,8 & B & $f$ & 8,8 & $D$ \\
\hline TCL 15008 & 3 & e & $156 \mathrm{f}$ & $76,2 \mathrm{~A}$ & $\mathrm{i}$ & 71,3 & B & $\mathrm{e}$ & 5,0 & $\mathrm{~F}$ \\
\hline TCL 15019 & 6 & e & $62 \mathrm{j}$ & $78,3 \quad A$ & $f$ & 69,4 & B & $f$ & 8,9 & $\mathrm{D}$ \\
\hline TCL 15022 & 10 & d & $62 \mathrm{j}$ & $74,6 \quad A$ & j & 69,5 & B & $f$ & 5,1 & $\mathrm{~F}$ \\
\hline TCL 15029 & 16 & $d$ & $62 \mathrm{j}$ & $76,0 \quad A$ & $\mathrm{i}$ & 68,2 & B & $g$ & 7,8 & D \\
\hline TCLD 0717 & 4 & e & 72 j & $79,7 \quad A$ & $d$ & 68,7 & B & $f$ & 11,1 & $B$ \\
\hline TCLD 0807 & 35 & $b$ & $62 \mathrm{j}$ & $71,8 \mathrm{~A}$ & $\mathrm{n}$ & 62,1 & B & j & 9,7 & C \\
\hline TCLD 0903 & 38 & $b$ & $62 \mathrm{j}$ & $75,7 \quad A$ & $\mathrm{i}$ & 71,4 & B & $\mathrm{e}$ & 4,4 & $\mathrm{~F}$ \\
\hline TCLD 1003 & 18 & d & $62 \mathrm{j}$ & $80,0 \quad A$ & $d$ & 67,8 & B & $g$ & 12,2 & A \\
\hline TLD 1103 & 6 & e & $64 \mathrm{j}$ & $68,8 \quad A$ & $p$ & 61,6 & B & j & 7,2 & $E$ \\
\hline TLD 1202 & 4 & e & 62 j & $73,8 \quad A$ & $\mathrm{k}$ & 65,3 & B & $\mathrm{h}$ & 8,6 & $D$ \\
\hline
\end{tabular}




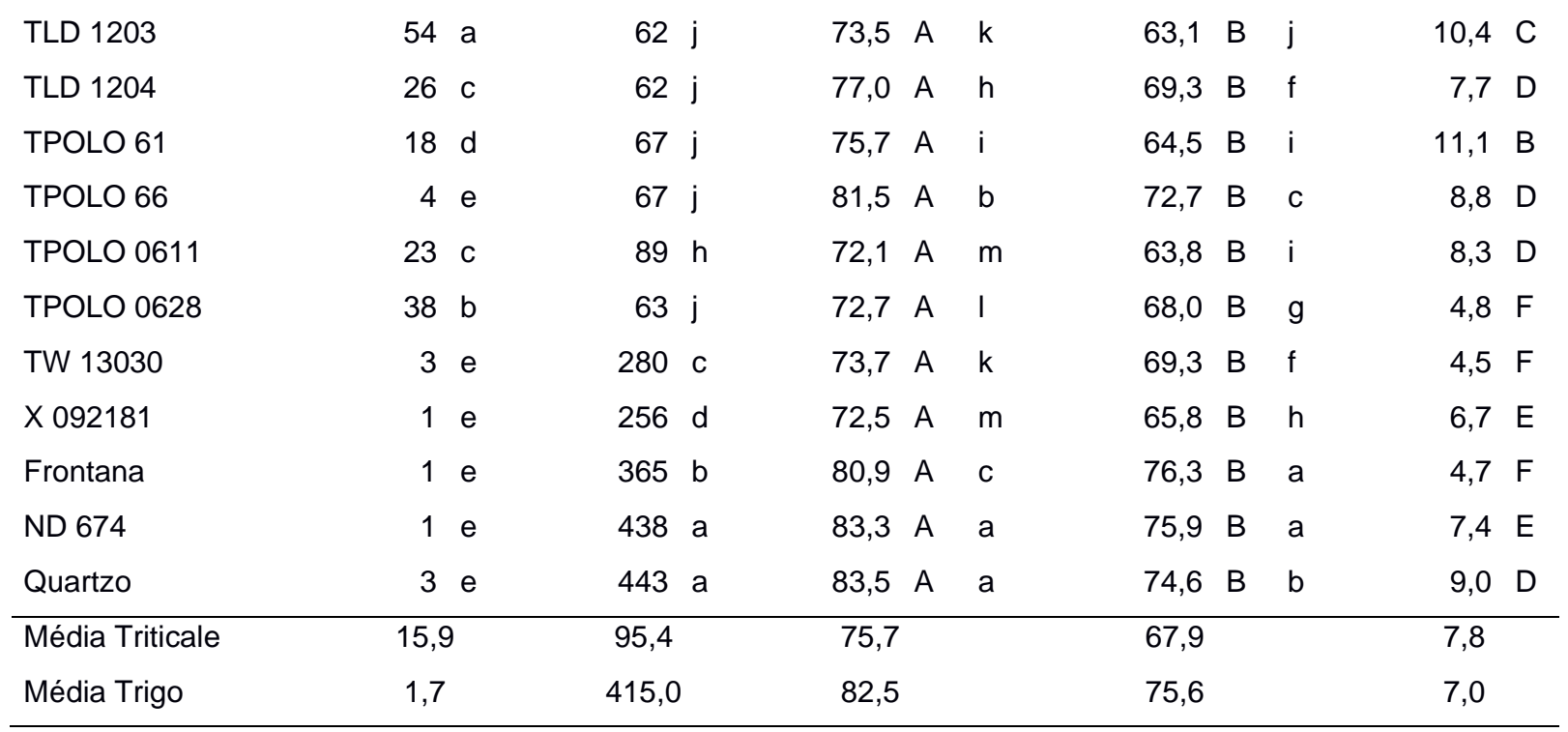

Médias seguidas pela mesma letra minúscula na coluna e maiúscula na linha constituem grupos estatisticamente homogêneos pelo teste de Scott-Knott a 5\% de probabilidade. \% GG = \% de Grãos Germinados; NQ = Número de Queda; PH sem = Peso Hectolítrico sem nebulização; PH com = Peso Hectolítrico com nebulização e RPH = Redução de Peso Hectolítrico.

Embora todos os genótipos tenham apresentado redução significativa de $\mathrm{PH}$, quando submetidos à nebulização, a magnitude desta redução foi distinta entre as cultivares (Tabela 2). Para o grupo de genótipos de triticale a RPH média foi de 7,8 kg/hl; mesmo para os trigos, com boa tolerância à PHS, a RPH média foi de 7,0 kg/hl. De maneira geral os genótipos de triticale apresentaram ampla variação para os caracteres $\mathrm{PH}$ com e sem nebulização e para a $\mathrm{RPH}$. Sendo que para a RPH destacaram-se os genótipos BRS Saturno, TCL 15008, TCL 15022, TCLD 0903, TPOLO 0628 e TW 13030, todos com RPH inferior a 5,2 kg/hl e classificados no grupo homogêneo da cultivar Frontana.

Ainda que nenhum dos genótipos de triticale tenham se equiparado aos genótipos de trigo quanto ao caráter $\mathrm{NQ}$, ampla variabilidade foi detectada entre os triticales para este caráter (Tabela 2). Foi constatado desde genótipos que apresentaram o valor mínimo registrável pelo equipamento "Falling Number" que é de 62 segundos, até genótipos com NQ superior a 250 segundos (BRS 203, TW 13030 e X 092181).

Neste estudo, diferentemente do que tem sido reportado para o trigo, a característica NQ não apresentou correlação com a tolerância à germinação na espiga 
em genótipos de triticale (Tabela 3). Isso talvez possa ser explicado pelo fato de que vários genótipos de triticale apresentaram o NQ mínimo que o equipamento "Falling Number" pode registrar.

O \% de grãos germinados correlacionou-se significativamente apenas com o peso hectolítrico dos grãos submetidos à nebulização, sendo a correlação negativa e de média magnitude. Isso indica que quanto maior o percentual de grãos germinados, menor tenderá a ser o peso hectolítrico dos grãos. Portanto, a quantificação do $\mathrm{PH}$ dos grãos submetidos à nebulização pode ser um método auxiliar ou alternativo para o screening de genótipos de triticale tolerantes à PHS.

Tabela 3. Estimativa dos coeficientes de correlação fenotípica entre os caracteres \% de Grãos Germinados, Número de Queda, Peso Hectolítrico com e sem nebulização e Redução de Peso Hectolítrico de 30 genótipos de triticale, Londrina-PR, safra 2016

\begin{tabular}{cccccc}
\hline Caráter & \%GG & PH sem & PH com & RPH & NQ \\
\hline \%GG & 1 & $-0,2368^{\text {ns }}$ & $-0,3622^{*}$ & $0,2204^{\text {ns }}$ & $-0,2869^{\text {ns }}$ \\
PH sem & 1 & $0,7928^{* *}$ & $0,2519^{\text {ns }}$ & $0,0377^{\text {ns }}$ \\
PH com & & 1 & $-0.39^{*}$ & $0,2145^{\text {ns }}$ \\
RPH & & & 1 & $-0,2807^{\text {ns }}$ \\
NQ & & & & 1
\end{tabular}

ns Não-significativo. * $\mathrm{e}^{* \star}$ Significativo a 5 e $1 \%$ de probabilidade, respectivamente, pelo teste t. \% GG $=\%$ de Grãos Germinados; NQ = Número de Queda; PH sem = Peso Hectolítrico sem nebulização; PH com = Peso Hectolítrico com nebulização e RPH = Redução de Peso Hectolítrico.

\section{DISCUSSÃO}

A classificação de genótipos de triticale no mesmo grupo dos trigos tolerantes à PHS, observada no presente estudo, indica que entre os genótipos de triticale avaliados existem potenciais fontes de tolerância para germinação pré-colheita. Por outro lado, a não discriminação destes genótipos pode indicar que a duração do teste de simulação de chuva não foi suficientemente longo para possibilitar a diferenciação dos acessos. 
Existem vários métodos descritos na literatura para avaliar a resistência à germinação na espiga (NEDEL et al. 1983a; HUMPHREYS; NOLL, 2002; GAVAZZA et $\mathrm{al}, 2012$ ). Independentemente dos procedimentos adotados para induzir a germinação e assim possibilitar a diferenciação dos genótipos, a maioria destes métodos utiliza-se da avaliação visual das sementes e o Número de Queda para quantificar a germinação e a correlacionada dormência das sementes.

A avaliação visual de sementes germinadas é uma das formas mais comuns de verificar a ocorrência de PHS em trigo e triticale, sendo a avaliação morfológica feita pela contagem das sementes germinadas. No entanto, o método de avaliação visual não permite a avaliação da extensão do prejuízo causado pela PHS na qualidade da semente, pois, esta depende de diferenças varietais e do estágio de germinação que as sementes se encontram. Uma vez que as sementes podem não apresentar germinação visível e, no entanto, apresentarem alta atividade enzimática indicando germinação, a avaliação através da quantificação do Número de Queda viria a suprir a deficiência da avaliação visual.

Embora o NQ seja um bom indicador da degradação do amido por várias enzimas ativadas durante o processo de germinação do trigo, Randhawa et al. (2015) ressaltam que o NQ do triticale não pode ser comparado diretamente com o do trigo porque fatores, além de alfa-amilase (por exemplo, determinadas enzimas endógenas e relações proteína-água), influenciam a viscosidade da solução de triticale.

Embora a variabilidade genética existente no triticale para a resistência à PHS e para o NQ seja menor que a disponível no trigo, ela parece ser suficiente para que, através do melhoramento genético, novas cultivares superiores possam ser geradas (NEDEL et al. 1983b; HAESAERT; DE BAETS, 1996; OETTLER, 2005; ALARU et al. 2008; BIZOVA et al. 2011). 


\section{CONCLUSÕES}

De uma maneira geral, quatro genótipos de triticale (BRS 203, BRS Netuno, BRS Saturno e TPOLO 66) destacaram-se por apresentar baixo \% de grãos germinados e manter o peso hectolítrico alto mesmo após serem expostos a 48 horas de nebulização.

\section{REFERÊNCIAS}

AACC. AMERICAN ASSOCIATION OF CEREAL CHEMISTS. Approved Methods of the American Association of Cereal Chemists. 10 ed. AACC, 2000.

ALARU, M.; LAURA Ü.; LAURINGSON, E. Pre-harvest sprouting tolerance of different winter triticale cultivars in the baltic sea area. Acta Agriculturae Scand Sect B-Soil and Plant Sci. v. 58, n. 1, p. 11-16, 2008.

BRASIL. Ministério da Agricultura, Pecuária e Abastecimento. Instrução normativa n. 38 de 30 de novembro de 2010. Regulamento Técnico do Trigo. Diário Oficial da República Federativa do Brasil, n. 29, Brasília, DF, 01 dez 2010. Seção 1. p. 2.

BASSOI, M.C.; FLINTHAM, J.; RIEDE, C.R. Analysis of preharvest sprouting in three Brazilian wheat populations. Pesquisa Agropecuária Brasileira, 41:583-590, 2006.

BIZOVA, I.; HROMADKO, M.; SVEC, K. Testing of pre-harvest sprouting of wheat and triticale at the breeding station Uhretice, Selgen Corp., Czech Republic. 62. Tagung der Vereinigung der Pflanzenzüchter und Saatgutkaufleute Österreichs, p. 109-110, 2011.

BONA, L. Triticale in Hungary. In: Mergoum M., Gómez-Macpherson H. (eds) Triticale improvement and production. 1 ed. Roma: FAO, v.1, p. 119-122, 2004.

CHAPMAN, B. Economic impact of pre-harvest sprouting, seed dormancy and germination from a famer perspective. Proc 12th Int Symp Pre-harvest sprouting in cereals, Alberta, Canada, p. 11, 2011.

CONAB - Companhia Nacional de Abastecimento. Acompanhamento da safra brasileira de grãos. v. 4. Safra 2016/17, n. 9 - Nono Levantamento. Brasília, 2017. Disponível em: <http://www.conab.gov.br >. Acesso em: 12 jun. 2017.

CRUZ, C.D. GENES - a software package for analysis in experimental statistics and quantitative genetics. Acta Scientiarum. v. 35, n. 3, p. 271-276, 2013.

ESTRADA-CAMPUZANO G.; SLAFER G.A.; MIRALLES D.J. Differences in yield, biomass and their components between triticale and wheat grown under contrasting water and nitrogen environments. Field Crops Res. v. 128, p. 167-179, 2012.

FAOSTAT. Food and Agriculture Organization of the United Nations. Disponível em: < http://faostat3.fao.org >. Acesso em: 14 dez. 2016 
FLINTHAM, J.E. Different genetic components control coat-imposed and embryo-imposed dormancy in wheat. Seed Science Research, v. 10, p. 43-50, 2000.

FRANCO, F.A.; PINTO, R.B.; SCAPIM, C.A.; SCHUSTER, I.; PREDEBON, C.T.; MARCHIORO, V.S. Tolerância à germinação na espiga em cultivares de trigo colhido na maturação fisiológica. Ciência Rural, v. 39, p. 2396-2401, 2009.

GAVAZZA, M.I.A.; BASSOI, M.C.; CARVALHO, T.C.; BESPALHOK FILHO, J.C.; PANOBIANCO, M. Methods for assessment of pre-harvest sprouting in wheat cultivars. Pesquisa Agropecuária Brasileira, v. 47, n. 7, p. 928-933, 2012.

HAESAERT, G; DE BAETS, A.E.G. Pre-harvest sprouting resistance in triticale: preliminary result. In GUEDES-PINTO, H.; DARVEY, N.; CARNIDE, V.P. (Eds.), Triticale: Today and Tomorrow, p. 615-622, 1996.

HIMI, E; MARES, D.J.; YANAGISAWA, A.; NODA, K. Effect of grain colour gene (R) on grain dormancy and sensitivity of the embryo to abscisic acid (ABA) in wheat. Journal of Experimental Botany, v. 53, p. 1569-1574, 2002.

HUMPHREYS, D.G.; NOLL, J. Methods for characterization of preharvest sprouting resistance in a wheat breeding program. Euphytica, v. 126, p. 61-65, 2002.

KUCERA, B.; COHN, M.A.; LEUBNER-METZGER, G. Plant hormone interactions during seed dormancy release and germination. Seed Science Research, v.15, p. 281-307, 2005.

KUO, A.; CAPPELLUTI, S.; CERVANTES-CERVANTES, M.; RODRIGUEZ, M.; BUSH, D.S. Okadaic Acid, a Protein Phosphatase Inhibitor, Blocks Calcium Changes, Gene Expression, and Cell Death Induced by Gibberellin. In: Wheat Aleurone Cells. The Plant Cell, v. 8, p. 259-269, 1996.

MARES, D.; MRVA, K.; CHEONG, J.; WILLIAMS, K.; WATSON, B.; STORLIE, E.; SUTHERLAND, M.; ZOU, Y. A QTL located on chromosome 4A associated with dormancy in white- and red-grained wheats of diverse origin. Theoretical and Applied Genetics, v. 111, p. 1357-1364, 2005.

MOŚ, M.; WÓJTOWICZ, T. The effect of seed sprouting damage on field emergence and yield of spring triticale. Journal of Central European Agriculture, v. 5, p. 251- 258, 2004.

NASCIMENTO JUNIOR, A; BAIER, A.C.; TEEIXEEIRA, M.C.C.; WIETHOLTER, S. Triticale in Brazil. In: MERGOUM, M.; MACPHERSON, H.G. (Org.). Triticale improvement and production. 1 ed. Roma: FAO, 1: 93-98, 2004.

NEDEL, J.L.; BAIER, A.C.; IGNACZAK, J.C. Comparação de testes para avaliar a germinação na espiga em triticale. Revista Brasileira Sementes, 5 (1), p. 75-80, 1983a.

NEDEL, J.L.; BAIER, A.C.; LINHARES, A.G.; DIAS, J.C.A. Avaliação de linhagens de triticale quanto à germinação na espiga. Revista Brasileira Sementes, 5 (2), p. 69-74, 1983b.

NÖRNBERG, R. Caracterização e predição de genitores visando à tolerância a germinação na pré-colheita em trigo (Triticum aestivum L.). (2012). 132f. Dissertação (Mestrado em Fitomelhoramento) - Faculdade de Agronomia Eliseu Maciel. Universidade Federal de Pelotas. Pelotas, 2012. 
OETTLER, G. The fortune of a botanical curiosity-Triticale: past, present and future. Journal of Agricultural Science, v. 143, p. 329-346, 2005.

OKUYAMA, L.A.; FONSECA JUNIOR, N.S.; CARAMORI, P.H.; KOHLI, M.M. Preharvest sprouting assessment in wheat genotypes influenced by temperature and degree days. Experimental Agriculture, p. 1-8, 2017. doi:10.1017/S0014479717000114.

RANDHAWA, H.S.; BONA, L.; GRAF R.J. Triticale breeding-Progress and prospect. In Eudes F. (ed) Triticale. Springer, New York, p. 69-81, 2015,

SEO, M.; NAMBARA, E.; CHOI, G.; YAMAGUCH, S. Interaction of light and hormone signals in germinating seeds. Plant Molecular Biology Reporter, v. 69, p. 463-472, 2009.

ZANETTI, S.; WINZELER, M.; KELLER, M.; KELLER, B.; MESSMER, M. Genetic Analysis of Pre-Harvest Sprouting Resistance in a Wheat x Spelt. Crop Science Society of America, v. 40, p. 1406-1417, 2000. 